\title{
Introduction special issue: topics in regional science in Israel and the Netherlands: housing markets, labour markets, economic activities, mobility and tourism
}

\author{
Jouke van Dijk ${ }^{1}$ - Amnon Frenkel ${ }^{2}$. \\ Jan Rouwendal ${ }^{3}$
}

(C) Springer-Verlag Berlin Heidelberg 2015

The economic crisis of recent years has further increased the importance of issues related to the development of space. This special issue presents a collection of papers that discuss these issues and are the result of a binational workshop on TOPICS IN REGIONAL SCIENCE IN ISRAEL AND THE NETHERLANDS: HOUSING MARKETS, LABOR MARKETS, ECONOMIC ACTIVITIES, MOBILITY AND TOURISM, jointly organized by the Israeli and the Dutch-speaking sections of the European Regional Science Association. The workshop took place at the University of Groningen on Thursday October 3 and Friday October 4, 2013 and was sponsored by the Faculty of Spatial Sciences.

The purpose of these bilateral workshops is to exchange ideas and promote collaboration on a variety of topics and methods in regional science research between the two countries. The bilateral workshops between the Dutch and the Israeli sections of the Regional Science Association have a long tradition going back almost 30 years. The first meeting was held in Herzlia, near Tel Aviv, Israel in 1988 and culminated

Jouke van Dijk

jouke.van.dijk@rug.nl

Amnon Frenkel

amnonf@technion.ac.il

Jan Rouwendal

j.rouwendal@vu.nl

1 Department of Economic Geography, Faculty of Spatial Sciences, University of Groningen,

Landleven 1, NL-9747 AD Groningen, The Netherlands

2 Urban and Regional Planning Program, Faculty of Architecture and Town Planning,

Technion-Israel Institute of Technology, Haifa, Israel

3 Department of Spatial Economics, Free University, De Boelelaan 1105, NL-1081 HV Amsterdam, The Netherlands 
in a book entitled: Location andLabor Considerationsof Regional Development, edited by F. Dietz, W. Heijman and D. Shefer, 1991 (published by Avebury Aldershot, UK). The second meeting took place in Tel Aviv in 1997 and culminated in a book entitled: Regional Development in an Age of Structural Economic Change, edited by P. Rietveld and D. Shefer, 1999 (published by Ashgate Publishing, Aldershot, UK). The third meeting was held in Utrecht, the Netherlands, in 1999 and the results of this meeting were published in a book entitled: Regions, Land, Consumption and Sustainable Growth, edited by O. Atzema, P. Rietveld and D. Shefer, 2005 (published by Edward Elgar Publishing, Cheltenham, UK). The fourth meeting took place in the Hebrew University of Jerusalem, Israel in 2008. The most recent workshop, that took place at the University of Groningen, was the fifth in the series and has led to several joint scientific activities.

Nine selected papers presented and discussed in the latest workshop are published in this special issue. The first two deal with housing markets in the Netherlands. The first paper, contributed by Dani Broitman and Eric Koomen, examines the regional diversity in residential development in the Netherlands. The authors investigate the spatiotemporal dynamics of housing stock on different scales using data on housing construction to demonstrate regional differences, especially between the national core economic area (the Randstad) and the rest of the Netherlands. They find that the Randstad - the western and most urbanized region of the country-is growing more than other regions. However, within the Randstad, the urban cores are growing less than could be expected given the generally accepted Gibrat's law of proportionate growth. Within the Randstad, the residential stock in the peri-urban zones grew faster than their initial size would suggest. In the second paper, Dennis Schoenmaker and Arno van der Vlist analyse the relationship between the commercial and residential real estate markets in the Netherlands using data on construction permits over the period 1990-2012. For the urban planning process, it is important to know whether the developments in both markets are substitutes or complementary. They conclude that residential and commercial real estate markets do not compete with each other in terms of land use and finances, and that developments in the two markets complement each other due to the fact that firms will locate near people and people will locate near firms.

The following two papers focus on the interaction between the housing market and the labour market. The third paper, by Amnon Frenkel and Sigal Kaplan, seeks to shed light on the housing preferences of knowledge workers in the Tel Aviv metropolitan area. Applying a joint multinomial-logit ordered-response model to the housing choices of business-oriented knowledge workers in high-tech services and financial business services, they analyse the joint residential choice of knowledgeworkers in terms of tenure, building type, location and dwelling size. The study found that a culture-oriented lifestyle prompts knowledge-workers to select small dwelling units in a central location, whereas a home-oriented lifestyle results in preferences for large-size apartments in suburb areas. The fourth paper, contributed by Yuval Kantor, Peter Nijkamp and Jan Rouwendal, provides new insights-both theoretical and empirical-into the relationship between home-ownership and job-search behaviour. Earlier empirical research using micro-level data found that unemployed homeowners are less inclined to change their residential location than unemployed 
renters to accept a new job elsewhere. This paper adds to the literature by addressing two complementary issues: the risk attitudes of job seekers and commuting costs. The authors show that a decrease in absolute risk aversion implies an increase in the exit rate from unemployment because, in the context of a standard job search model, long-term unemployment implies a risk of being forced to sell one's house. In a spatial setting, this result implies that higher housing costs increase average commuting distances. The empirical results show that homeowners have higher exit rates from unemployment than tenants. However, there was no evidence that higher housing costs are associated with higher exit rates from unemployment.

The aim of the fifth paper, by Arjen Edzes, Marije Hamersma, Viktor Venhorst and Jouke van Dijk, was to shed light on the determinants of a decision to continue in education because it is well known that those with low education levels and school dropouts are least successful in the labour market. They showed that regional factors have a significant impact on the decision to continue (or not) in education and on the likelihood of getting a job. The most striking finding is that a prosperous regional labour market stimulates individuals to accept a job and drop out of school before they achieve the minimum level of schooling necessary to be successful on the labour market in the long run. They seem to prefer the short-term benefit of earning money above an investment in schooling of which the benefits will occur in the future. However, personal aspects and school/education satisfaction are found to be at least as relevant as the regional labour market in determining school continuation decisions and labour market outcomes of low-educated school-leavers. They also find evidence for positive spillovers between higher and lower educated workers, but no evidence of negative crowding-out effects.

The sixth paper, contributed by Tal Modai and Pnina Plout, discusses intrametropolitan residential mobility and income segregation. They look at how residential mobility and income sorting are intertwined and investigate the gains in neighbourhood status of relocating households in the Tel Aviv metropolitan region. The authors argue that the upward mobility of higher-income households leads, in turn, to income sorting. They find that, on average, movers experience positive neighbourhood gains. Neighbourhood upgrades are an integral part of the progress associated with housing. With regard to income-sorting dynamics, they find that income groups are differentiated by the extent of temporal changes in neighbourhood gains. Residential mobility patterns throughout the research period reflected increasing spatial differentiation between high- and middle-income movers. Spatial differentiation also increased between highand low-income movers and between middle- and low-income movers in parallel with housing price declines. Spatial differentiation decreased between these groups in parallel with price appreciation.

The seventh paper by Nataliya Rybnikova and Boris Portnov offers a new approach for identifying clusters of economic activities using data from light-at-night satellite measurements. Identifying clusters of economic activities is an important step in devising regional development policies. However, a major problem with the identification of such clusters stems from the limited reporting by countries and administrative entities on the regional distribution of specific economic activities, especially for small regional subdivisions. In this study, they investigate whether 'missing' data on geographic concentrations of economic activities in the European NUTS3 regions can 
be constructed using light-at-night satellite measurements, and whether such reconstructed data can then be used for cluster identification. The basis is that night-time light, captured by satellite sensors, is characterized by different intensities depending on its source: production facilities, services, etc. Their analysis indicates that mean light-at-night intensities are able to identify several types of economic activities, performing especially well for professional, scientific and technical services, for public administration, as well as for arts, entertainment and recreation, thus helping to supplement limited information and assist in regional analysis.

The final two papers deal with the impact of communication technologies (CTs) and visa restrictions on international travel and tourism. The eighth paper, by Anat Tchetchik, examines whether communication at a distance and travel to meet in person compete with or complement each other in the case of travel to meet immigrants' relatives and whether and to what extent each of the diverse "technology encounters" plays a different role in this regard. Drawing upon two bodies of knowledge on travel and tourism as well as the social networks literature, an empirical specification that explains the frequency of travel to meets immigrants' relatives is specified. Based on a sample of 300 Israeli respondents, the study shows that a high frequency of communicating at a distance is associated with a high travel frequency, and that the medium matters: a heavy use of only certain CTs corresponds with more frequent travel to meet in person. In particular, communication through tools such as Facebook and Skype constitutes, to some extent, a substitute for face-to-face meetings. The ninth and final paper, authored by Michal Beenstock and Daniel Felsenstein, tests the visaled tourism hypothesis (VTH) which contends that easing visa restrictions increases international tourism. Israel acts as a natural laboratory for this with clear before and after junctures in visa restrictions. Using panel data, on tourism to Israel from 60 countries during 1994-2012, they estimate that partial waivers of visa restrictions increase tourism by $48 \%$ and complete waivers increase tourism by $118 \%$. Other results address the adverse effect of Israel's security situation on tourism, the beneficial effect of real devaluation on tourism and the fact that the elasticity in tourism to Israel relative to all destinations is very small.

Overall, the nine papers in this special issue represent unique perspectives on complex regional issues in Israel and the Netherlands related to the housing and labour markets, and the interactions between the two through commuting and migration in a dynamic regional economic context, and also the tourism sector. The bilateral workshops involving the two countries are an excellent way to exchange ideas and promote collaboration on a variety of topics and methods in regional science research, and the next workshop is already under preparation. We hope that this special issue will stimulate other national or language-based sections of the regional science community to start bilateral workshops that encourage a more in-depth way of learning about regional issues and also strengthen the personal relationships between regional scientists that may foster future cooperation and joint research activities and publications. 